\title{
Seven essential messages for the time of the coronavirus
}

\author{
Anna Wierzbicka \\ Australian National University
}

\section{Message 1}

It is good for all of us if we think like this every day now:

This time is not like other times

Very bad things are happening to many people now.

Very bad things are happening to many people's bodies because of the coronavirus, many people are dying because of this.

More people can die if I do some things now as I have always done. I don't want this.

Because of this it will be good if I can be at home all the time.

If I have to be not at home for some time, I will think like this all the time:

I don't want to be near other people; I don't want to be so near some one that I can touch them.

I don't want to be so near someone that I can breathe the same air.

\section{Message 2}

It is good for all of us if we think like this every day now:

This time is not like other times.

Very bad things are happening to many people now.

Many people feel something very very bad.

I can do some good things for some of these people;

I want to do something good for them.

I want to know what I can do; I want to think about it today;

I want to do something today. 


\section{Message 3}

It is good for all of us if we think like this every day now:

This time is not like other times.

During this time many people can't be with other people as before.

They can't speak to other people like before; many people feel something very bad because of this.

I know some of these people. I want these people to know that I am thinking about them.

I want them to know that I don't want bad things to happen to them.

I want to do something because of this.

Perhaps I can write to them, perhaps I can ring them, something like this; I want to do something today.

\section{Message 4}

It is good for all of us if we think like this every day now:

This time is not like other times.

Very bad things can happen to me during this time, not like at other times.

At the same time, I can do some very good things during this time, not like at other times.

I can do many things "good for the soul", not like at other times.

I can read books, listen to music, write something every day about this day, things like that.

If I pray, I can pray more; If I don't pray, I can do something like it.

I can look at the stars at night, I can look at the sky when the sun is rising, things like that.

I want to do these things. I want to do these things today.

\section{Message 5}

It is good for all of us if we think like this every day now:

This time is not like other times.

I don't want to think about it like this:

Very bad things are happening now, nothing good can happen because of this.

I want to think like this:

I can do some very good things during this time, not like at other times.

If I do these things, after this bad time I can be not as I was before:

I can know some people better, I can love some people more.

I want this. 


\section{Message 6}

It is good for all of us if we think like this every day now:

This time is not like other times.

I can't live during this time as I lived before.

At the same time, I can think about many things more, not as before.

I can think more about things like this:

Why do I live on earth? What do I live for? How can I live if I want to live well?

If I know that I will die soon, what do I want to do before I die?

If I think about these things more now, after this bad time I can live not as I lived before.

I can then live in another way, I can live better.

I want this.

\section{Message 7}

It is good for all of us if we think like this every day now:

This time is not like other times.

We can't live during this time as we lived before.

At the same time, we can think about some things more now, not as before.

We can think about things like this:

We all live with other people, none of us is like an island.

How can we live well with other people?

We can think about the earth; we can think like this:

We live on earth now, many people will live on earth after us.

We don't want very bad things to happen to these people.

If we think about these things more now,

after this bad time we can live not like before; we can live better.

We want this.

Canberra, Australia

29/4/2020 


\section{Семь важных мыслей во время коронавирусной пандемии}

\section{Анна Вежбицкая}

Австралийский Национальный Университет

\section{Мысль первая}

Будет хорошо для нас всех, если мы будем думать сейчас каждый день так:

Это время не такое, как в обычное время.

Очень плохие вещи происходят сейчас со многими людьми.

Очень плохие вещи происходят сейчас с телами многих людей из-за коронавируса, многие люди умирают из-за этого.

Еще больше людей может умереть, если я буду делать то, что делал всегда; я этого не хочу.

Поэтому будет хорошо, если я буду все время дома.

Если в какое-то время я не смогу быть дома, я буду все время думать так:

Я не хочу быть рядом с другими людьми, я не хочу быть так близко к другим,чтобы их коснуться.

Я не хочу быть так близко к другим, чтобы дышать тем же воздухом.

\section{Мысль вторая}

Будет хорошо для нас всех, если мы будем думать сейчас каждый день так:

Это время не такое, как обычное время.

Очень плохие вещи происходят сейчас со многими людьми.

Многие люди чувствуют из-за этого что-то очень плохое.

Я могу сделать что-то хорошее для этих людей, я хочу сделать что-то хорошее для них.

Я хочу знать, что я могу сделать, я хочу сегодня об этом подумать, я хочу сделать что-то сегодня.

\section{Мысль третья}

Будет хорошо для нас всех, если мы будем думать сейчас каждый день так:

Это время не такое, как обычное время.

В это время многие люди не могут быть с другими людьми, как раньше. 
Они не могут, как раньше, говорить с другими людьми, многим людям очень плохо из-за этого.

Я знаю таких людей. Я хочу, чтобы они знали, что я о них думаю.

Я хочу, чтобы они знали, что я не хочу, чтобы с ними случилось что-то плохое.

Я хочу что-то сделать для этого.

Может, я могу написать им, может я могу позвонить им.

Я хочу что-то сделать сегодня.

\section{Мысль четвертая}

Будет хорошо для нас всех, если мы будем думать сейчас каждый день так:

Это время не такое, как обычное время.

Очень плохие вещи могут произойти со мной в это время.

В то же время я могу сделать сейчас что-то очень хорошее, не как в обычное время.

Я могу сделать сейчас много хорошего для души.

Я могу читать книги, слушать музыку, каждый день писать что-то об этом дне.

Если я молюсь, я могу молиться больше; если я не молюсь, то я могу делать что-то подобное.

Я могу смотреть на звезды ночью, смотреть на небо когда восходит солнце, что-то такое.

Я хочу это делать. Я хочу это делать сегодня.

\section{Мысль пятая}

Будет хорошо для нас всех, если мы будем думать сейчас каждый день так: Это время не такое, как обычное время.

Я не хочу думать об этом так:

Очень плохие вещи происходят сейчас.

Ничего хорошего не может произойти из-за этого.

Я хочу думать так:

Я могу сделать много хорошего в это время, не как в обычное время.

Если я буду это делать, после этих плохих времен я могу быть не таким, как раньше.

Я смогу узнать некоторых людей лучше, я смогу любить некоторых людей больше.

Я этого хочу. 


\section{Мысль шестая}

Будет хорошо для нас всех, если мы будем думать сейчас каждый день так: Это время не такое, как обычное время.

Я не могу в это время жить, как я жил раньше.

В то же время я могу думать о многих вещах больше.

Я могу думать о таких вещах:

Почему я живу на этой земле? Для чего я живу?

Как мне жить, если я хочу жить хорошо?

Если я знаю, что скоро умру, что я хочу сделать до того, как я умру?

Если сейчас я буду больше об этом думать,

после этих плохих времен я смогу жить не так, как раньше.

Я смогу жить по-другому, я смогу жить лучше.

Я этого хочу.

\section{Мысль седьмая}

Будет хорошо для нас всех, если мы будем думать сейчас каждый день так:

Это время не такое, как обычное время.

Мы не можем жить в это время так, как жили раньше.

В то же время мы можем думать о некоторых вещах больше.

Мы можем думать о таких вещах:

мы все живем с другими людьми, никто из нас не похож на остров.

Как нам жить с другими людьми хорошо?

Мы можем думать о земле; мы можем думать так:

мы живем на земле теперь, многие люди будут жить на земле после нас;

мы не хотим, чтобы с этими людьми произошло что-то очень плохое.

Если сейчас мы будем думать об этом больше, после этих плохих времен мы сможем жить не так как раньше; мы будем жить лучше.

Мы этого хотим. 